\title{
VIOLÊNCIA NO TRABALHO EM SAÚDE: ANÁLISE EM UNIDADES BÁSICAS DE SAÚDE DE BELO HORIZONTE, MINAS GERAIS
}

\author{
VIOLENCE IN HEALTH WORK: ANALYSIS OF BASIC HEALTH UNITS IN BELO HORIZONTE, \\ MINAS GERAIS
}

\author{
Cássia Beatriz Batista ${ }^{1}$ \\ Augusto de Souza Campos ${ }^{2}$ \\ Juliana do Carmo Reis ${ }^{3}$ \\ Virgínia Torres Schall ${ }^{4}$
}

Resumo O presente estudo buscou investigar e compreender a violência vivenciada em unidades básicas de saúde (UBSs) da perspectiva dos processos de trabalho em saúde. A caracterização da violência nesse contexto, ao identificar e compreender os elementos da produção desse fenômeno, contribui para o seu enfrentamento. De cunho descritivo-exploratório, para a coleta de dados a pesquisa utilizou grupos focais e entrevistas com usuários, trabalhadores e gestores do serviço de saúde. O estudo mostra as consequências e os impactos da violência nas UBSs, retratando atitudes geradas pelos episódios de violência, bem como ações preventivas e mecanismos de apoio e suporte. A análise dos resultados marca a necessidade de se fortalecer não só a humanização e a gestão do trabalho em saúde, mas também a formação dos profissionais, atrelada às melhorias nas condições e no ambiente de trabalho e, consequentemente, na prestação dos serviços de saúde.

Palavras-chave violência no trabalho, processo de trabalho, saúde, unidade básica de saúde.
Abstract This study sought to investigate and understand the violence experienced in basic health units (UBS) from the perspective of the work processes carried out in health. The characterization of the violence existing in this context, achieved by identifying and understanding the elements that cause this phenomenon, contributes to combating it. Descriptive and exploratory, this study gathered data from focus groups and interviews carried out among health service users, employees and managers. The investigation shows the consequences and impacts of violence in the UBSs, portraying attitudes generated by episodes of violence, as well as preventive actions and mechanisms of support and assistance. The analysis of the results shows not only there is a need both to strengthen the humanization and management of the work in health and to train the area's professionals, but also that these actions should be linked to improved workplace environment and conditions and, thus, better health service provision.

Keywords workplace violence; work process; health; basic health unit. 


\section{Violência no trabalho}

Abordando a violência como um risco para a saúde individual e coletiva, a Organização Mundial da Saúde (OMS), em seu relatório sobre a temática (Krug et al., 2002), define violência como o uso intencional de força física ou de poder, em ameaça ou ato, contra si mesmo, outra pessoa, grupo ou comunidade, que resulte em ou tenha grande probabilidade de causar lesão, morte, agravo psicológico, distúrbios de desenvolvimento ou privação.

De forma mais específica, a Organização Internacional do Trabalho (OIT) (Organização Internacional do Trabalho, International Council of Nurses e Organização Mundial da Saúde, 2003a, 2003b ou 2003c) enfoca a violência na condição de fenômeno presente no trabalho, definindo a expressão workplace violence - violência no local de trabalho - como qualquer ação, evento ou comportamento voluntários em consequência dos quais uma pessoa é agredida, ameaçada ou sofre algum dano ou lesão durante a realização do seu trabalho - ou como resultado de suas atividades nele.

As definições de violência na área da saúde tendem a ter uma visão abrangente da saúde quando consideram as consequências da violência. Dessa forma, além dos agravos físicos, consequências de caráter moral e psicológico não podem ser negligenciadas. Segundo Schnieden (1993), a pessoa-alvo de um ato violento pode experimentar reação de estresse agudo, manifestada por despersonificação, desrealização e obnubilação. Caso os sintomas persistam ou se intensifiquem, é possível o desenvolvimento da síndrome de estresse pós-traumático, com hipersensibilidade ou negação do evento traumático. Mesmo não desenvolvendo qualquer desestabilização psicológica grave, Hofeldt (2001) sustenta que a experiência de uma agressão no trabalho altera definitivamente a prática do profissional.

O programa conjunto Workplace Violence in the Health Sector (Organização Internacional do Trabalho, International Council of Nurses e Organização Mundial da Saúde, 2002) ressalta que a violência no trabalho na área da saúde pode comprometer a acessibilidade aos serviços, pela dificuldade na manutenção de quadros, em especial na atenção básica. Assim, em geral, considera-se que a violência no trabalho em saúde pode levar à redução da disponibilidade de serviços e ao aumento dos custos. Essa situação dificulta a contratação e a manutenção de trabalhadores. Porém, ainda que isso não ocorra, os trabalhadores que se mantêm no serviço podem ser conduzidos a estratégias de defesa e evitação, com consequências negativas para o desenvolvimento das atividades.

Nos serviços de saúde, os efeitos indiretos da violência no trabalho, tais como o desestímulo para o trabalho, as estratégias de evitação do risco, em prejuízo do atendimento, e a dificuldade na manutenção e na contratação de quadros impactam a qualidade do serviço e é possível que representem 
um custo importante e invisível da violência (LeBlanc e Kelloway, 2002; Schat e Kelloway, 2000; Rogers e Kelloway, 1997). Se, por um lado, a violência pode prejudicar o serviço prestado, por outro, ela também pode ser causada pela insatisfação dos usuários com a qualidade do atendimento, gerando um ciclo vicioso que retroalimentaria o problema.

Das diversas formas que os custos da violência podem assumir, além das mortes, as mais evidentes talvez sejam aquelas relativas aos dias de trabalho perdido e aos gastos com tratamento médico e psicológico, com reparos em instalações e equipamentos, ou, ainda, com processos judiciais e indenizações aos trabalhadores.

Atualmente, diversas pesquisas vêm procurando conhecer o perfil epidemiológico da violência no trabalho. Contudo, as divergências de definição (Campos, 2002; Santos Junior, 2004), a inexistência de fontes específicas de dados e a própria característica de invisibilidade do problema nas organizações vêm dificultando a complementaridade dos estudos. Dessa forma, apesar do número significativo de pesquisas encontradas na literatura, as informações são ainda insuficientes para uma visão geral do problema.

Embora a violência atinja os mais diversos, e praticamente todos, os setores produtivos, podem-se perceber formas, configurações e gravidades específicas. Toscano e Weber (1995), partindo da expressão fatal e não fatal ao caracterizar a violência no trabalho, demonstram que a maioria das mortes se relaciona a assaltos e roubos, e que homens trabalhadores em bares e restaurantes, no comércio varejista e no transporte urbano são as suas principais vítimas. Já as principais vítimas de violência não fatal são mulheres profissionais de serviços de saúde. Outros estudos (Toscano e Weber, 1995; Toscano e Windau, 1994; Duhart, 2001) confirmam que a área de saúde registra aproximadamente $25 \%$ de todas as ocorrências de violência no espaço de trabalho, e que os trabalhadores da saúde estão entre os mais atingidos pelas agressões.

Nos últimos anos no Brasil, trabalhadores, sindicatos e gestores do setor, em especial da atenção básica (Campos, 2004) e dos serviços de urgência e emergência (Deslandes, 2000), voltaram sua atenção para o problema. Muito embora exista certo consenso acerca da relevância e dos impactos da violência nos trabalhadores e no próprio funcionamento do sistema, há pouca informação sistemática sobre a violência em serviços de saúde. De modo geral, o conhecimento sobre a questão baseia-se no relato informal de casos e em notícias divulgadas pela imprensa. São ainda poucas as pesquisas e incipientes os sistemas de notificação dedicados aos eventos de violência no trabalho.

O presente estudo visa melhor caracterizar a compreensão sobre a violência vivida nas unidades básicas de saúde (UBSs), na perspectiva dos processos de trabalho em saúde, buscando enfatizar a importância da humanização e 
da gestão do trabalho, bem como da educação permanente dos profissionais de saúde, a fim de gerar ações para o enfretamento e a promoção de melhorias no ambiente de trabalho e na prestação dos serviços de saúde.

\section{Percurso metodológico}

Esta pesquisa qualitativa de cunho descritivo-exploratório baseou-se em um protocolo da OMS (Krug et al., 2002) e da OIT (Organização Internacional do Trabalho, International Council of Nurses e Organização Mundial da Saúde, 2003a, 2003b, 2003c) e em um estudo adaptado no Brasil por Palácios (2003). O protocolo é composto de duas partes; delas, a primeira é qualitativa e se utiliza de grupos focais, com trabalhadores e gestores, recorte desta pesquisa. As entrevistas e os grupos focais foram orientados por um roteiro definido, traduzido e adaptado desse protocolo, roteiro que contempla as seguintes questões: definições de violência, interpretações individuais e institucionais e atitudes diante da violência, compreensões sobre o contexto da violência no trabalho, estratégias de controle da equipe de saúde e identificação de apoios, lacunas e sugestões relativos à violência no trabalho.

A técnica de grupos focais adotada é utilizada com frequência para a obtenção de informações em profundidade, da perspectiva dos indivíduos, a partir de sua realidade social e de uma construção dialógica do posicionamento do grupo. A reunião do grupo é coordenada por moderador que ao mesmo tempo deve manter a fluidez da comunicação no grupo e a discussão em torno da temática, cobrindo os diversos tópicos apontados no roteiro (Kind, 2004).

Chama-se atenção para o fato de a metodologia da pesquisa apreender especificamente as visões e reflexões dos participantes sobre temas previamente definidos. Trata-se, então, de experiências e depoimentos dos sujeitos - no caso, dos trabalhadores que desenvolvem suas atividades cotidianamente nessas UBSs. Os dados qualitativos produzidos foram analisados segundo o método da análise temática de conteúdo proposto por Bardin (1977), de modo a categorizá-los e interpretá-los, após uma leitura flutuante de todo o material por dois pesquisadores.

Para a realização do estudo, a Prefeitura de Belo Horizonte indicou um distrito de saúde de Belo Horizonte, composto de 18 UBSs, e outros quatro estabelecimentos de saúde, nas áreas de saúde mental, emergência e farmácia. O distrito, com uma população de 270 mil pessoas aproximadamente, está dividido em 68 bairros, conta com 38 escolas municipais e 75 praças e parques ecológicos, e apresenta áreas de médio e alto risco de vulnerabilidade social. 
Após a aprovação da pesquisa pelo Comitê de Ética em Pesquisa da Secretária Municipal de Saúde da Prefeitura de Belo Horizonte (CEP/SMSA/PBH), protocolo n. 037/2006, a coleta de dados foi realizada de janeiro a julho de 2007, mediante entrevistas e grupos focais gravados e posteriormente transcritos.

Os grupos focais foram constituídos por meio de convites enviados às unidades de saúde do distrito. Solicitava-se que fosse encaminhado um profissional de cada categoria para a participação nas discussões. Depois de repassado o convite pelas gerências, a participação nos grupos foi voluntária, podendo o participante ausentar-se em qualquer momento, como explicitado pelo mediador no momento de realização do grupo e na leitura e assinatura do Termo de Consentimento Livre e Esclarecido.

Os encontros ocorreram durante o horário de funcionamento das UBSs, em espaços disponibilizados pela Prefeitura de Belo Horizonte, e tiveram a duração de 90 a 150 minutos, com participação total de 75 pessoas e média de sete pessoas por grupo. Todas as unidades do distrito participaram. É importante destacar que os grupos focais com participação inferior a cinco pessoas foram repetidos, 5 a fim de garantir confiabilidade dos dados obtidos.

A realização dos grupos focais foi inicialmente acertada com chefias e gerências; foi fundamental a formação de grupos homogêneos (mesmas categorias profissionais e/ou nível hierárquico). Ou seja, separadamente, os 12 grupos foram reunidos por categorias de trabalho da seguinte maneira: 11 agentes comunitários de saúde; sete enfermeiros; quatro médicos; três gerentes de UBSs; cinco gerentes distritais; quatro profissionais do núcleo psicossocial (assistente social, psicólogo e psiquiatra); seis profissionais da equipe de saúde bucal (dentista e técnico de higiene dental); sete auxiliares e técnicos de enfermagem; oito auxiliares administrativos; seis porteiros; oito auxiliares de serviços gerais; e seis usuários.

Além dos grupos, foram realizadas três entrevistas com profissionais dos seguintes órgãos gestores: Secretaria Adjunta de Saúde, Gerência de Assistência do Município e Gerência de Projetos Especiais; e uma entrevista com um integrante da diretoria do Sindicato dos Servidores Municipais de Belo Horizonte (Sindibel).

É importante destacar que a equipe de pesquisa6 estabeleceu, em 2007, um vínculo com o distrito pesquisado e participou de três reuniões para discutir a questão da violência nas UBSs. Esses encontros contaram com a participação de gerentes e profissionais das UBSs, profissionais do distrito sanitário, representantes da Secretaria Municipal de Saúde (SMSA), da Guarda Municipal, da Polícia Militar, do Centro de Estudos de Criminalidade e Segurança Pública (Crisp/UFMG) e do Núcleo de Estudos em Educação e Saúde Coletiva (Nescon/UFMG). 


\section{Resultados e discussão}

Os dados sobre idade, tempo de serviço e gênero apresentam variedade entre os participantes, ressaltando-se que a maioria deles são mulheres, dados reafirmados como representativos do setor de saúde. Entretanto, as análises dos perfis dos profissionais e da percepção da violência em cada categoria profissional separadamente, as diferenças de gênero, idade, vínculo trabalhista e tempo de serviço não foram recortes realizados nesta análise. Esse recorte, bem como a questão da 'fala oficial' dos gestores constituem aspectos importantes do estudo, que serão analisados em outro momento. De qualquer modo, vale destacar que os gestores e gerentes apresentam um posicionamento de mediação entre a crença na política de atenção básica do município - e nos seus serviços e profissionais - e o desejo de que seja implantada, e os limites e desafios decorrentes dos escassos recursos, do despreparo dos profissionais, das precárias condições de trabalho e da enorme demanda da população.

Por meio do recorte definido para este estudo, que correspondeu a uma análise geral dos depoimentos de todos os participantes da pesquisa, identificaram-se quatro categorias, que serão apresentadas e discutidas: estratégias individuais diante da violência; respostas institucionais e mecanismos de apoio e suporte; consequências e impactos da violência; e ações preventivas.

\section{Estratégias individuais diante da violência}

Foram incluídas nessa categoria as estratégias que os trabalhadores diretamente envolvidos ou não em episódios de violência adotam para gerir conflitos e agressões, de forma a garantir a execução de suas tarefas e/ou administrar as cargas e os impactos em sua atividade decorrentes da violência no trabalho.

Os trabalhadores revelam atitudes tanto de conformismo quanto de inconformismo - por exemplo, com respostas individuais ante as agressões diante dos episódios. Os profissionais inconformados reclamam da situação com os diversos níveis de gestão e se sentem indignados com a situação:

Agora, tem uma coisa que me preocupa: eu tenho uma funcionária da farmácia que está extremamente indignada com a forma como o pessoal a trata. Eu vejo que muitos já se acostumaram e não reclamam; agora, ela reclama. (...). Ela está inconformada e ela não vai se conformar (Gerente de UBS).

Mesmo com iniciativas da prefeitura de Belo Horizonte e do Sindibel visando incentivar a notificação e outros procedimentos institucionais de denúncia e suporte, observa-se forte presença no discurso dos profissionais 
de uma postura de conformismo no que diz respeito aos episódios de violência. Tal situação pode revelar uma espécie de apatia ou passividade do profissional diante da questão:

Porque, por exemplo, você está na fila lá, você está atendendo na marcação, você pode sofrer ameaça, mas eles não falam. Depois que começou a ser discutida a questão da violência - "Olha, gente, vamos notificar, vamos chamar a Guarda Municipal para fazer o boletim de ocorrência, o CAT e tal" - um ou outro faz [notifica]. Aí eu pergunto: - "Por que você não vai fazer?" [E eles respondem:] - "Ah, deixa pra lá". Então, do mesmo jeito que eles se sentem ameaçados e preocupados, eles também não estão preocupados em saber por que isso está acontecendo e informar sobre isso. Eu acho que é o conformismo: - “Ah, isso é assim mesmo" (Gerente de UBS).

Na tentativa de compreender os motivos do conformismo dos profissionais ante os episódios de violência, os dados permitiram levantar algumas hipóteses: a falta de punição do agressor, a percepção da corresponsabilidade no processo de violência, a responsabilidade da instituição e o fato de o profissional ser o representante legal dessa instituição:

Talvez seja porque não acontece nada com o usuário, ou porque (...), de repente, ele se sente também com uma parcela de culpa ou, talvez, quando [o problema é] instituído ou instituinte. Por exemplo, às vezes o paciente precisa tomar um medicamento, aquele trem todo, mas não tem. E como se faz? Então, quem começou essa violência foi a instituição, a partir do momento em que ela prometeu o remédio e não tem! A pessoa grita com o funcionário, e ele..., eu acho que ele entende que ela não tem culpa. “Eu vou apanhar aqui porque não tem remédio e eu sou o representante do governo!" Qual a solução disso? É abastecer a farmácia. É uma forma de prevenir (Gerente de UBS).

Em relação a essa demanda, existe a ideia de que determinados conhecimentos técnicos podem contribuir para um melhor manejo do usuário. Entretanto, verifica-se que apenas a polidez não garante a prevenção da violência. Além da postura de acolhimento e respeito, das explicações claras, do trato e manejo na relação profissional-usuário, é preciso ter condições de prestar a assistência, ou seja, são necessários os insumos e a infraestrutura adequada. Isso é de responsabilidade do Estado e nem sempre está disponível nos serviços.

\section{Respostas institucionais e mecanismos de apoio e suporte}

Por respostas institucionais, compreende-se todo o tipo de ação política institucional mais ou menos formalizada que tem como objeto o problema 
da violência e seus efeitos. De acordo com as diretrizes da OIT e o protocolo utilizado (Krug et al., 2002; Organização Internacional do Trabalho, International Council of Nurses e Organização Mundial da Saúde, 2003a), os mecanismos de resposta institucional incluem atividades institucionais formais - entre outras, procedimentos de notificação, investigação do evento e ações sobre o agressor - após a ocorrência de violência.

As ações ou procedimentos institucionais são vistos pelos trabalhadores como importante suporte para conflitos e episódios de violência ocorridos no serviço. As respostas institucionais ocorrem em três níveis: centro de saúde, distrito e secretaria municipal.

De acordo com os relatos, na maioria das vezes os episódios de violência são percebidos como parte do trabalho, não havendo necessidade ou interesse de providências outras que as estratégias utilizadas pelos trabalhadores individual e coletivamente. Geralmente são situações de conflito ou de insatisfação do usuário, nas quais a interação se degrada em alguma forma de rispidez, insinuação, insulto ou pequena ameaça. Nesses casos, apesar de os trabalhadores citarem algum tipo de desgaste, geralmente descrito como tensão ou estresse, não há encaminhamento nem resposta institucional.

Contudo, quando ocorre um episódio de violência considerado grave como agressões físicas ou ameaças repetidas -, o fato tende a mobilizar o trabalhador ou mesmo a equipe. Quando isso acontece, o estudo revela que o primeiro procedimento é a comunicação do evento à gerência do distrito. De acordo com a gravidade da situação, o nível distrital pode deslocar um funcionário para o centro de saúde, a fim de que ele avalie a situação e dê suporte aos profissionais e à comunidade. Em casos excepcionais - por exemplo, quando toda a equipe está ameaçada como resultado de situações relacionadas à criminalidade - o secretário municipal de Saúde pode ser acionado:

O enfrentamento da questão na hora! Gera ou não gera um fechamento da unidade? Porque, uma premissa nossa aqui é, salvo em situação extrema, nós não vamos fechar o centro de saúde por causa de ação de bandido! Então, primeiro [é preciso] essa decisão do dia e da hora; depois, uma conversa com todos os trabalhadores e, muitas vezes, o afastamento daquele mais diretamente envolvido (Gestor da SMSA).

Em casos de maior gravidade, o principal papel dos profissionais deslocados para o local é atuar como mediadores entre as partes. A postura adotada é de escuta dos envolvidos e de análise da situação. Com isso, busca-se a solução do conflito ou o retorno à possibilidade de negociação de formas não violentas. Em conjunto com a equipe da unidade, decide-se sobre a necessidade do fechamento temporário do centro de saúde - por causa do sentimento de medo e insegurança, por exemplo -, a intervenção do grupo de trabalho de humanização e/ou o remanejamento de profissionais (Trajano, 
2007). O fechamento da unidade, ainda que provisório, é considerado última alternativa - raramente é utilizado; para que ocorra, a Secretaria Municipal de Saúde precisa ser acionada:

Primeira coisa é o seguinte: qualquer episódio que aconteça, a orientação que se tem, que a gente cobra de nossos gerentes, é que imediatamente o nível distrital se desloque para a unidade, a fim de dar apoio aos trabalhadores, para estar junto com eles (Gestor da SMSA).

E assim, no início, a gente tenta também sempre ouvir o trabalhador e ouvir o usuário. Tem uma orientação para que seja feita uma entrevista com o trabalhador agredido e com o usuário que foi o agredido ou o agressor (Gestor da SMSA).

Outra ação relatada é a solicitação da presença da Guarda Municipal e da Polícia Militar no local para mediar conflitos. Em algumas situações, busca-se garantir também a segurança dos trabalhadores e usuários, e o registro do fato como ocorrência policial. Após as respostas imediatas, quando se julga que há risco para o trabalhador a ponto de inviabilizar sua permanência na unidade, ou quando se avalia que ele não apresenta condições psicossociais para continuar naquela localidade ou atividade, pode-se optar pela sua transferência ou afastamento temporário, descrito como medida última, na ausência de outras possibilidades:

Em última instância, quando não tem jeito, é [preciso] retirar o trabalhador daquele lugar e colocar em outro. Afastar durante um tempo, se for necessário, para que ele possa elaborar (Gestor da SMSA).

Outro procedimento institucional é a notificação ou o preenchimento da CAT.7 As informações sobre a existência de instrumentos, mecanismos e fluxos formais para a notificação 8 de violências no trabalho foram desconexas, sugerindo que esses instrumentos são pouco conhecidos e pouco utilizados pelos trabalhadores. Além disso, muitas vezes os trabalhadores relatam não ter interesse na notificação, desconhecer os seus desdobramentos e considerar que ela é de pouca utilidade ou resultado em suas realidades de trabalho. Esse fato é confirmado pela fala dos representantes do sindicato.

Após a ocorrência dos eventos, há dispositivos institucionais de apoio ou suporte que visam reparar agravos sofridos ou evitar o desenvolvimento de danos maiores. Esses mecanismos incluem serviços de aconselhamento, atenção médica e debriefing, ${ }^{9}$ dentre outros. Podem também prever formas de elaboração coletiva de saberes e de propostas para a gestão da atividade, das cargas de trabalho do grupo e, em especial, dos problemas relacionados aos episódios de violência. 
Muito frequentemente, a necessidade de capacitação ou preparo para o trabalho foi expressa nos grupos como forma de apoio e suporte aos trabalhadores:

Teoricamente, para atender uma pessoa, você teria de estar preparada e assistida, seja por um psicólogo, porque você também tem coisas atrás de você - e, para ajudar o outro, ouvir o outro, tentar dar um caminho para o outro, você também tem de estar recebendo ajuda, porque vai acumulando todas aquelas pressões da sua vida normal e daquilo tudo que você recebe. Quando um profissional de saúde conversa com um usuário, ele está num papel não só de chegar e atender: o cara quer ser ouvido. E tem um momento ali em que você tem de parar e escutar. E você escuta os problemas da pessoa e assimila os problemas, por mais que você tente ser indiferente... (...).

Tem também a própria dificuldade de cuidar de si mesmo. Se você adoece, é uma dificuldade o profissional de saúde ser atendido, ser levado, chegar até o finalmente, porque a estrutura não traz esse atendimento (...). Nenhum profissional consegue fazer um bom trabalho se não tem o apoio para isso - e aí vem a estrutura, e aí vem a parte médica, psicológica. Você está lidando com o povo (Gerente de distrito).

Por sua vez, a demanda de suporte profissional para os trabalhadores, especialmente àqueles que são vítimas de violência, mas não unicamente, é concebida como um meio eficaz para ajudar a lidar com as cargas de trabalho:

Nós ficamos oito horas da nossa vida por dia ali dentro, fora as outras coisas, e não tem ninguém para acolher a gente. Nós tentamos acolher todo mundo muito bem, mas não tem ninguém para acolher a gente. Quando a gente pergunta alguma coisa, só faltam bater na gente: "Mas o que é isso, você ainda não sabe isso?" Olha, gente, não é assim não... Então não tem ninguém para me acolher? Tem dias em que você está passando dificuldades. Você tem coisas fora do serviço, você não só trabalha não: tem sua vida fora do serviço, tem um emocional que está dançado também, está cheio de problemas, com problema na família, com problema em casa, com problema financeiro. No entanto, não tem ninguém para acolher a gente; a gente até releva então o que acontece! (Enfermeiro).

Em caso de violência, a primeira forma de suporte é a escuta individualizada pelo gerente do centro de saúde ou do nível distrital. Após essa escuta e a análise do caso, o trabalhador pode ser encaminhado para o Núcleo de Apoio Sociofuncional (Nasf); entretanto, esse núcleo ainda não está implantado completamente, e muitos profissionais desconhecem o serviço:

Não [existe suporte]. (...) Existe o Nasf. (...) Mas o Nasf não é para violência. (...) Mas tem algumas ações. [Vocês conhecem algum profissional que foi agredido e 
que foi encaminhado para o Nasf?] Não. (...) Teoricamente, o que eu conheço é a palestra do Nasf, mas na prática, comigo, não (Gerente de UBS).

As atividades e estruturas de suporte aos profissionais envolvidos em episódios de violência ainda têm cobertura limitada e estão em construção. O fluxo adequado deveria ser o perito avaliar o caso e encaminhar o profissional para o atendimento médico ou psicológico e/ou a licença. Nos casos onde ocorre violência física, o profissional deve ser encaminhado para a perícia médica. Contudo, muitos entrevistados, principalmente os de nível médio, desconhecem a existência da assistência psicológica aos trabalhadores:

Quando aconteceu essa ameaça à gerente, uma médica entrou em depressão violenta e não conseguiu voltar à unidade. Eles tentaram remanejá-la, mas nenhum suporte foi oferecido a ela, emocional, psicológico, nada (Profissional do Núcleo Psicossocial).

(...) eu falo muito dessa solidão do servidor quando ele é agredido, porque ele fica muito sozinho. Não tem mecanismo de proteção... (Gerente de distrito).

Apesar dos três níveis de ação e respostas institucionais, para algumas categorias profissionais ainda prevalece o desconhecimento desses mecanismos, talvez pela falta de informação ou pela pouca sistematização do fluxo de ação, permanecendo a percepção de desamparo:

Eu, no meu caso pessoal, quando sofri uma violência, (...) não tive nenhum respaldo; assim, meus colegas foram chamados para testemunhar... (...) Agora, a instituição não tomou conhecimento (Profissional do Núcleo Psicossocial).

A verdade é a seguinte: se você tomar um tapa no centro de saúde, ninguém paga (Auxiliar administrativo).

Como resposta institucional, alguns poucos participantes da pesquisa sabiam da existência de grupos de discussão organizados pelo programa de humanização do serviço público de saúde HumanizaSUS, 10 como as chamadas Redes de Valorização e Cuidado aos Trabalhadores da Saúde, que oferecem suporte psicossocial por meio da troca de experiências e da construção coletiva de estratégias de enfrentamento.

Em Belo Horizonte, em julho de 2004, foi constituído o Grupo de Trabalho da Humanização (GTH), com representantes das diversas gerências do nível central.11 De acordo com alguns relatos, essa experiência ainda tem alcance limitado na rede, sendo pouco conhecida por seus trabalhadores. Entretanto, observou-se o desejo e o empenho por parte da SMSA de ampliar o projeto: 
Nós temos um trabalho com mais ou menos trinta centros de saúde dessas áreas de risco. Durante dois anos, a gente criou momentos de discussão, de troca de experiências, para aprender a como lidar com isso. Então a gente vem discutindo o que a gente chama de mediadores de conflito; tentando formar mediadores de conflitos para essas áreas (Gestor da SMSA).

As ações de humanização previstas na política nacional de humanização HumanizaSUS também são apontadas como estratégias preventivas, valorizando os diferentes sujeitos implicados no processo de produção de saúde - usuários, trabalhadores e gestores - e buscando processos de autonomia, o protagonismo, a corresponsabilidade, o estabelecimento de vínculos solidários e a participação coletiva no processo de gestão.

\section{Consequências e impactos da violência}

Reações ou efeitos ocorridos na UBS e em seus sujeitos, mais especificamente impactos na saúde do trabalhador, na organização do trabalho e no serviço prestado, foram revelados pela pesquisa. Os dados retratam que a violência interfere na organização do trabalho e em seus processos por causa da grande rotatividade de profissionais, da dificuldade de lotação de novos funcionários e do número de transferências de trabalhadores, fatores que desestruturam as equipes de trabalho:

É muito ruim a ocorrência de um episódio de agressão verbal ou física: é muito desestruturante, muito ruim. (...) Ter que tirar pessoas de um lugar -e, às vezes, a gente tem de fazer isso mesmo, porque ela foi ameaçada de morte e hoje em dia não dá para você achar que isso não vai acontecer - na maioria dos casos não acontece, mas você não vai apostar que não vai acontecer (Gestor da SMSA).

Além disso, a violência no trabalho se reflete em adoecimentos, medos, insatisfação e em outros sentimentos de insegurança e desmotivação por parte dos profissionais, comprometendo a saúde do trabalhador:

Cai a qualidade e contagia todo mundo. Desmotiva todo mundo. De tudo o que eu faço nada é valorizado. Você é agredido, você não vale nada, entendeu? E é triste, você fica chateado mesmo. E o conjunto todo, toda a equipe fica desmotivada, chateada (Gerente de UBS).

[A violência] Causa doenças no funcionário, o funcionário fica estressado, fica com problemas físicos e mentais, desmotivado, sem incentivo (Auxiliar e técnico de enfermagem). 
Meu estômago vive doendo; vivo tomando Buscopan. Fico estressada, porque a gente se sente impotente, a gente tem vontade de fazer alguma coisa, mas não consegue. Está além da nossa capacidade (Auxiliar administrativo).

Davidson e Jackson (1985), Lanza (1983 e 1985) e Ryan e Poster (1989) relatam que agravos cognitivos, emocionais e físicos podem estar presentes por longos períodos após o retorno da vítima ao trabalho. Trabalhadores agredidos experimentam depressão, medo, diminuição da autoconfiança, síndrome de estresse pós-traumático, distúrbios do sono, irritabilidade, apresentando problemas no relacionamento familiar e com colegas, diminuição da sua eficiência no trabalho e aumento do absenteísmo.

Outra consequência da violência incide na prestação de serviço: além da equipe incompleta ou constantemente renovada e dos medos e adoecimentos, a redução do horário de funcionamento das unidades, o fechamento provisório da UBS e a pouca interação com os usuários impactam na qualidade dos serviços prestados:

Às vezes, a gente tem de reduzir o horário de funcionamento: temos um horário de funcionamento-padrão de 7 às 19 horas, mas algumas unidades são autorizadas a fechar uma hora mais cedo (Gestor da SMSA).

De modo geral, os profissionais se declaram preocupados e consternados com a violência no trabalho. Em sua percepção, ela tem aumentado gradativamente, atingindo o cotidiano de trabalho de todos, e eles se preocupam com as consequências que a violência acarreta tanto para os trabalhadores quanto para o funcionamento do serviço.

Nota-se que a ausência ou a reduzida permanência dos profissionais nas UBSs são influenciadas pela precariedade das condições de trabalho, que afeta os processos de trabalho e a saúde do trabalhador, e, por sua vez, a qualidade do serviço, tornando-se mais um fator causal da violência no setor da saúde. Percebe-se, assim, a circularidade na produção da violência que acomete a área de saúde: um impacto ou consequência da violência causando outras violências. Esse ciclo deve ser compreendido em suas dimensões política, governamental, social, institucional e comunitária.

\section{Ações preventivas diante da violência nas unidades básicas de saúde}

As diversas formas de violência precisam ser encaradas da perspectiva da violência estrutural, presente em instituições, costumes e crenças, que imprime injustiças e perdas a determinados indivíduos e grupos. Na aplicação do conceito de prevenção à violência, deve-se considerar ainda o 
contexto social, histórico e a realidade local de determinada sociedade (Minayo e Souza, 1998).

Diversas intervenções no processo de trabalho que provoquem mudanças dos fatores ou criem barreiras na ocorrência dos eventos violentos podem ser adotadas como medidas preventivas. Ressalta-se que as ações preventivas devem decorrer dos condicionantes, dos desencadeadores e das causas da violência. Entretanto, na maioria das vezes, as ações preventivas descritas se referem apenas a determinadas causas que se restringem ao âmbito local ou à relação usuário-profissional.

Entre as diversas ações de prevenção, deu-se grande ênfase nas estratégias individuais para evitar a ocorrência dos episódios. A atitude mais citada foi a conduta pessoal ou a forma de contato com o paciente, geralmente descrita como uma abordagem mais cordial e com disponibilidade:

Muitas vezes, a forma como você fala é o que desencadeia o processo de agressividade. Você tem várias formas de falar um não. Então, às vezes, o funcionário já está estressado, depressivo ou com algum problema, e ele transfere isso para o usuário - e vice-versa. Essa forma de pensar duas vezes, respirando ao abordar o paciente, chamando-o pelo nome, eu acho que já é, de certa forma, válida (Auxiliar de enfermagem).

Uma boa conversa. Se o usuário está nervoso, você chega calmamente e vai tentando 'apacientar' e escutar. Você tem de aprender a falar (...) Não é o sujeito estar alterado e você alterar também. É aprender a falar e a ouvir (Porteiro).

A ênfase no contato hostil com o usuário como fator desencadeador de episódios de violência é encontrada especialmente na fala de gerentes, gestores e usuários, mas também está presente na fala das equipes de saúde das UBSs. Trata-se de uma concepção de que polidez, cordialidade e empatia são capazes de responder às expectativas e de apaziguar os conflitos vividos no serviço.

Por outra parte, os participantes também mencionam que, principalmente para os médicos, a formação universitária direcionada para o trabalho no Sistema Único de Saúde (SUS), com enfoque nas necessidades da população e na saúde pública, ajudaria a prevenir a violência. Tal formação auxiliaria no atendimento e no acolhimento ao usuário, diminuindo as possibilidades de conflito.

Embora conflitos e atos de violência não possam ser atribuídos exclusivamente às condutas individuais, a frequência e a ênfase como desencadeadoras dadas a elas nos depoimentos indica que são primordiais na produção dos episódios. Nessa perspectiva, o foco é colocado no contato entre o trabalhador e o usuário, sendo a formação vista como uma ferramenta para 
melhorar a interação com o usuário. Essa concepção, contudo, coloca em segundo plano não apenas a organização do serviço (as condições materiais e técnicas da produção) - um dos aspectos mediadores dessa relação -, mas também a diminuição da violência estrutural, decorrente da melhoria da qualidade de vida da população, como forma de prevenção à violência. Enfatizar a formação dos profissionais em sua abordagem e relação com o usuário do SUS não é suficiente para modificar a realidade violenta, na qual estão presentes outros aspectos que influem na relação trabalhador-usuário.

Também foram apontados, como estratégias preventivas, o programa HumanizaSUS, a estratégia de utilização de recursos preferenciais, o vínculo com a comunidade e a medida institucional - considerada a de maior impacto - de atuação da Guarda Municipal nos centros de saúde. Os sujeitos afirmaram que a presença da Guarda Municipal tem inibido ações de violência, principalmente porque ela tem contato direto com a Polícia Militar, mesmo que os guardas não portem armas e que as ações não sejam 'punitivas' ou 'restritivas':

A gente não acredita que a força seja a solução não, mas eu estava ouvindo [no rádio] (...) que foram reduzidas em $40 \%$ as situações de conflito nas unidades básicas com a chegada da guarda. E ainda não tem em todas! (Gestor da SMSA).

Alguns trabalhadores acham que a ação da Guarda Municipal é muito limitada e defendem uma ação mais incisiva, inclusive com a presença de homens armados, naquelas comunidades que convivem com maior presença da criminalidade. Para os representantes dos usuários, a implantação da Guarda Municipal foi um ganho para todos os cidadãos, principalmente pelo fato de estarem ali para proteger um patrimônio público, garantindo o atendimento da população. Segundo os gestores, no entanto, o papel de polícia não deve ser a tônica da atuação da Guarda Municipal. Seu caráter principal é descrito como "educativo ou preventivo". Para isso, o guarda municipal recebe treinamento específico para atuar na área da saúde:

A gente, daqui da saúde, participa da capacitação deles: eles são formados, e nós falamos basicamente dessa missão da saúde, porque eles não podem ir para lá também com esse espírito de polícia. E eles são importantes mediadores com a polícia também, porque muitas vezes o trabalhador tem medo de chamar a polícia, e o guarda faz isso pela gente, porque é mais tranquilo do que um trabalhador ameaçado chamar. Então, a gente tem um trabalho muito em conjunto. A gente é atendido prontamente, quando é o caso dessa contenção, vamos dizer assim (Gestor da SMSA).

O papel da Guarda Municipal é visto de maneiras distintas. Para alguns, principalmente os gestores, a guarda tem um caráter mediador; para outros, 
seu papel é de controle e disciplinamento do comportamento dos usuários, o que deixa implícita a necessidade da presença de um terceiro ordenador.

Outra forma de prevenção citada pelos gestores é a identificação das unidades que apresentam mais conflitos e a alocação estratégica de recursos humanos e materiais para tais UBSs. Essas unidades estão localizadas, geralmente, em regiões de alta vulnerabilidade social e nelas há a ocorrência frequente de episódios de violência contra o trabalhador, sendo a principal delas a ameaça verbal. Essa estratégia de recursos preferenciais busca garantir a manutenção do profissional na unidade, o fornecimento de materiais e, consequentemente, um melhor atendimento à população:

Do ponto de vista cultural, (...) identificar as unidades que têm potencialmente mais conflitos e ter um olhar especial para elas na questão de material, medicamentos, locação de recursos. Para isso, nós temos um trabalho aqui na Secretaria [Municipal de Saúde] que identificou mais ou menos 35 unidades críticas, para as quais existe um conjunto de medidas de proteção, vamos dizer assim, a serem tomadas. Uma delas, além de chamar os profissionais do concurso - que a gente deve chamar no máximo em 15 dias -, é a equiparação dos salários do contrato administrativo com o [salário do pessoal] efetivo, para atrair mais profissionais para essas unidades (Gestor da SMSA).

Muitos mecanismos têm sido criados para garantir a presença dos profissionais lá [na unidade de saúde]: diferenciação de salários, proteção diferenciada, lotação de guarda - nós temos desenvolvido um grupo, um grupo de reflexão, com profissionais que trabalham nessas unidades (Gestor da SMSA).

Contudo, com essa estratégia, corre-se o risco de beneficiar umas localidades e gerar outro tipo de conflitos. Ela pode ser eficaz, como ação emergencial e pontual, quando articulada a ações globais e estruturais para combater a violência de forma mais ampla.

Aqui reaparece, agora como ação preventiva, o projeto Redes de Valorização e Cuidado aos Trabalhadores da Saúde, que busca desenvolver uma metodologia de intervenção para favorecer processos de diálogos e de análises coletivas e formas de mediação dos conflitos. Todavia, como já indicado nas respostas institucionais, poucos declararam conhecer essa ação.

Já o projeto Caixa da Paz é mais difundido entre os trabalhadores. Ele consiste na troca de bilhetes entre trabalhadores e usuários, e não se trata de uma 'caixa de reclamações'. O intuito do projeto é criar um espaço para que as pessoas possam registrar suas opiniões, demandas e reivindicações, procurando formas menos conflituosas ou agressivas.

Para os trabalhadores, tal iniciativa só tem efetividade se as críticas discutidas em equipe, e, quando necessário, com a comunidade - indiquem 
caminhos para a solução dos problemas. Entretanto, por causa da sobrecarga de trabalho nos centros de saúde, muitas vezes essas discussões permanecem em segundo plano.

Sobre o vínculo com a comunidade, os momentos com os grupos operativos e as reuniões com a comissão local propiciam, de acordo com os informantes, maior aproximação da comunidade e fortalecem o vínculo e a construção conjunta de alternativas diante da violência vivenciada:

Uma coisa que foi feita lá, eu até não achava interessante não, mas depois eu vi, surtiu efeito. Chamaram a polícia e a comissão local de saúde. Eles foram informados do que a gente estava vivendo e nos ajudaram a trabalhar isso com a população, para tentar diminuir um pouco essa violência. Porque as pessoas precisam do centro de saúde aberto... Então, isso foi uma coisa interessante. Isso foi uma iniciativa lá do centro de saúde (Profissional do Núcleo Psicossocial).

A atuação de representantes da comunidade no centro de saúde, por possibilitar a formação de vínculos, é percebida como de extrema importância para a prevenção da violência. A necessidade de ampliar ações com a comunidade é ressaltada pelos entrevistados:

Então, nesses casos mais complicados, [é necessário] um trabalho com a comunidade no sentido de que as pessoas entendam o que é o centro de saúde (Gestor da SMSA).

A gente fez durante um ano uma ouvidoria com a comissão local. Eu percebi que a ouvidoria seria uma alternativa, porque quando você ouve a comunidade, chegam coisas que não chegavam para a gente, assim, de forma objetiva (Gerente de UBS).

É importante destacar que certas categorias profissionais, principalmente as de nível médio e fundamental (auxiliares administrativos, porteiros e auxiliares de serviços gerais), não identificam a existência de nenhum tipo de prevenção. Além disso, alguns trabalhadores ressaltam que as ações existentes não estão igualmente presentes em todas as unidades. Dessa forma, parece necessário fortalecer a divulgação das ações, assim como sua maior institucionalização e difusão no sistema, procurando ampliar o acesso a elas.

A escassez de recursos financeiros e a extensão da rede pública de saúde de Belo Horizonte foram apontadas como dificultadoras, mesmo que sejam evidentes as iniciativas da Prefeitura de Belo Horizonte visando à busca de recursos extras em âmbito nacional e estadual:

Houve outra ocasião (...) em que a nossa unidade foi assaltada oito vezes consecutivas em dois meses. O recurso que tivemos foi o de chamar a imprensa. E, a partir da imprensa, as providências foram tomadas pela Prefeitura. O gerente intermediou 
isso, informou o que estava se passando, e o distrito tomou algumas providências, tipo [colocar] grades nas janelas (Profissional do Núcleo Psicossocial).

A fim de aprimorar as estratégias de prevenção, insistiu-se na melhoria das estruturas de atendimento, no abastecimento das unidades, na composição das equipes, na capacitação profissional e na sensibilização/informação da população quanto ao funcionamento do Sistema Único de Saúde e da Estratégia de Saúde da Família (ESF).

Silveira (2007) menciona algumas ações que podem funcionar como providências precoces e interromper uma cadeia de eventos: neutralização ou minimização de fatores que contribuem para a ocorrência dos eventos; intervenções nos mecanismos que levam ao agravo; e, também, fortalecimento dos fatores de proteção contra o agravo. Nesse sentido:

Então, quando a gente consegue trabalhar uma comunidade para ela entender o problema e virar parceira do sistema de saúde, a coisa caminha mais tranquila. Existe a violência, mas ela fica mais fácil de ser trabalhada (Gerentes de distrito).

Ao lado das iniciativas já em curso, tem-se dado ênfase à criação de estruturas regionais para o atendimento psicológico e jurídico; a capacitação dos profissionais do distrito para lidar com o trabalhador agredido; e a qualificação da perícia médica e sua integração com as estruturas de suporte ao trabalhador.

É importante compreender que a mudança no modelo de atenção básica à saúde exige formação da equipe e também do usuário. Essa nova proposta, caracterizada como ação preventiva, que prima não só pela proximidade e maior participação dos usuários no serviço de saúde, mas também pela desconstrução do antigo modelo, requer diferentes habilidades e posturas profissionais no trabalho que estão sendo aprendidas no cotidiano da implantação do serviço, nas relações entre trabalhadores e usuários, um usuário que reivindica mais por seus direitos, porém que ainda não tem clareza sobre o funcionamento da rede de serviço - além das limitações do equipamento público para cumprir sua função de forma satisfatória. Esse período de mudança cultural apresenta conflitos que podem gerar episódios de violência que se somam aos fatores externos e estruturais da violência urbana.

\section{Considerações}

Sabe-se que a violência não é uma especificidade da nossa época. Ela está presente de diferentes formas em toda a história e em todas as sociedades humanas (Minayo, 1994). Considera-se também que medidas de controle ou 
de dissuasão de comportamentos violentos não são suficientes para a construção de uma sociedade segura.

Leather (2001) observa que vem ganhando força a ênfase no papel das características individuais para a produção de episódios de violência no trabalho em detrimento de fatores situacionais. Algumas características individuais podem servir como indicadores de uma maior probabilidade de ações violentas, mas certamente essas ações não ocorrem independentemente do contexto. No caso do setor saúde, o tipo de serviço parece ser ainda um dos preditores mais importantes para a violência.

Todo o cenário que envolve os episódios de violência - condicionantes, fatores causais e desencadeadores - gera consequências tanto para a instituição quanto para os profissionais e usuários. Assim, configura-se como demanda legítima a minimização de episódios que infringem o direito de liberdade e a dignidade dos cidadãos envolvidos no setor da saúde.

O estudo retrata que a violência no local de trabalho é um fator presente no cotidiano dos trabalhadores da rede de saúde de Belo Horizonte e que essa violência tem causado problemas para o desenvolvimento do trabalho. As respostas e as ações para evitar os episódios de violência são pontuais, ou individualizadas ou locais, atingindo na maioria das vezes os desencadeadores e raramente os fatores causais ou os condicionantes de uma perspectiva da violência estrutural.

Pautando-se em uma compreensão cíclica da produção da violência, as ações preventivas, por sua vez, deveriam atingir todas as dimensões envolvidas e apontadas até aqui pelo estudo. Existe, porém, uma distância entre as causas e os motivadores da violência no trabalho em saúde identificados e descritos pela pesquisa e as respostas estabelecidas ou colocadas para o seu enfrentamento. Com isso, é necessária a implantação de políticas e instrumentos de avaliação dos casos de forma contextualizada e a análise dos resultados das medidas de enfrentamento e prevenção dos episódios de violência atualmente adotadas.

Nesse sentido, as políticas nacionais de humanização e de educação permanente em saúde (Brasil, 2004) podem fortalecer a construção coletiva de respostas para o enfrentamento da violência e de ações preventivas a ela, focalizando a gestão e o processo do trabalho, bem como a formação de recursos humanos para atuarem no setor da saúde, em sua complexidade de cuidado dos sujeitos de uma sociedade.

Enfatiza-se, então, a necessidade de ampliar as ações para a formação dos trabalhadores, a mudança institucional e organizacional do trabalho no setor da saúde e a transformação cultural, processo esse construído coletivamente, nos embates, na negociação de saberes e na promoção de autonomia para que novas práticas de saúde sejam reinventadas (Peixoto e Batista, 2009). 
Assim, como indicado neste estudo, o enfrentamento da violência implica a formulação de políticas gerais e também a implantação de ações voltadas para o processo de trabalho nas UBSs e no sistema de saúde como um todo, com a participação integrada de trabalhadores, poder público e sociedade civil, visando melhorias estruturais nas relações sociais e no trabalho em saúde, tendo em vista as necessidades da população no que diz respeito ao serviço de saúde prestado.

\section{Nota do Editor}

Artigo extraído do Relatório da pesquisa "Violência no trabalho: estudo em unidades básicas de um distrito sanitário de Belo Horizonte", financiada pelo Conselho Nacional de Desenvolvimento Científico e Tecnológico (CNPq), edital MCT/CNPq/MS-DAB/SAS n. 049/2005, processo n. 40.2247/2005-1. Belo Horizonte: Laboratório de Educação em Saúde e Ambiente (Laesa), Fiocruz/MG; Departamento de Medicina Preventiva e Social da Universidade Federal de Minas Gerais; Laboratório de Psicologia Social da Pontifícia Universidade Católica de Minas Gerais, abril de 2008.

\section{Notas}

1 Professora da Pontifícia Universidade Católica de Minas Gerais (PUC Minas), Belo Horizonte, Brasil. Mestre em Psicologia Social pela Universidade Federal de Minas Gerais (UFMG). <cassiabeatrizb@gmail.com>

Correspondência: Rua Walter Ianni, 255, CEP 31.980-110, São Gabriel, Belo Horizonte, Minas Gerais.

2 Psicólogo e pesquisador na Organização Pan-Americana da Saúde (Opas). Mestre em Saúde Pública pela Universidade Federal de Minas Gerais. <augustosc@gmail.com>

3 Pesquisadora na Fundação de Desenvolvimento da Pesquisa da Universidade Federal de Minas Gerais (UFMG) e psicóloga da Prefeitura Municipal de Belo Horizonte, Minas Gerais, Brasil. Mestre em Psicologia pela Universidade Federal de Minas Gerais (UFMG). <julianadocarmo@yahoo.com.br> 
4 Psicóloga, pesquisadora titular, chefe do Laboratório de Educação em Saúde e Ambiente - Laesa, CPqRR/Fiocruz, Belo Horizonte, Minas Gerais, Brasil. Doutora em Educação pela Pontifícia Universidade Católica do Rio de Janeiro (PUC-Rio).<vtschall@cpqrr.fiocruz.br>

5 Apesar da repetição dos grupos, nos casos dos grupos de médicos, gerentes e núcleo psicossocial não foi possível garantir participação de pelo menos cinco profissionais em cada grupo.

6 Além dos autores deste artigo, a equipe também foi da consultora Elizabeth Costa Dias e do auxiliar de pesquisa André Diniz.

7 A lei determina que toda doença profissional ou acidente do trabalho seja comunicado pela empresa ou instituição ao Instituto Nacional do Seguro Social (INSS). A comunicação de acidente de trabalho (CAT) é um registro importante, que gera informações para o campo previdenciário, trabalhista, estatístico e epidemiológico.

8 Para Machado e Minayo Gomez (1994), os dados da CAT são problemáticos, pois além de as comunicações só levarem em conta os trabalhadores inseridos no mercado formal, existe ainda o problema da subnotificação por parte das empresas.

9 O debriefing psicológico é uma intervenção, conduzida por pessoal treinado, em período imediatamente posterior a catástrofes ou situações traumáticas; ele permite que as vítimas falem de suas experiências e recebam informações sobre reações 'normais' a tais eventos. Existem diversos métodos descritos, contudo, em geral, o debriefing é uma intervenção realizada em sessão única, semiestruturada, conduzida em momento brevemente após o evento, visando à prevenção de respostas psicológicas adversas (Rose e Tehrani, 2002).

10 Para conhecer mais sobre o programa de humanização HumanizaSUS e, especificamente, sobre as Redes de Valorização e Cuidado aos Trabalhadores da Saúde, ver Brasil (2006).

11 Hoje o GTH se amplia com a participação dos distritos, unidades e do Conselho Municipal da Saúde.

\section{Referências}

BARDIN, Laurence. Análise de conteúdo. Lisboa: Edições 70, 1977.

BRASIL. Ministério da Saúde. Secretaria de Atenção à Saúde. Núcleo Técnico da Política Nacional de Humanização. Trabalho e redes de saúde: valorização dos trabalhadores da saúde. 2. ed. Brasília, DF: Ministério da Saúde, 2006.

Ministério da Saúde. Secretaria Executiva. Núcleo Técnico da Política Nacio- nal de Humanização. HumanizaSUS: gestão e formação nos processos de trabalho. Brasília, DF: Ministério da Saúde, 2004.

CAMPOS, Augusto S. A violência no trabalho como objetivo da saúde do trabalhador das unidades básicas de saúde do distrito sanitário norte de Belo Horizonte. 2004. Dissertação (Mestrado em Medicina Preventiva e Social) - Departamento de Medicina Preventiva e Social, Universidade Federal de Minas Gerais, Belo Horizonte, 2004. 
Violência e trabalho. In: MENDES, René (org.). Patologia do trabalho. 2. ed. rev. ampl. São Paulo: Atheneu, 2002.

DAVIDSON, Paul; JACKSON, Craig. The Nurse as a Survivor: Delayed Post-Traumatic Stress Reaction and Cumulative Trauma in Nursing. International Journal of Nursing Studies, v. 22, n.1, p.1-13, 1985.

DESLANDES, Suely Ferreira. Violência no cotidiano dos serviços de emergência: representações, práticas, interações e desafios. 2000. Tese (Doutorado em Ciências na Área de Saúde Pública) - Escola Nacional de Saúde Pública, Fundação Oswaldo Cruz, Rio de Janeiro, 2000.

DUHART, Detis T. Violence in the Workplace, 1993-99. Bureau of Justice Statistics Special Report. National Crime Victimization Survey. Washington (D.C.): U. S. Department of Justice, Dec. 2001. Disponível em: http:// bjs.ojp.usdoj.gov/index.cfm?ty=pbdetail\& iid=693. Acesso em: 24 maio 2011.

HOFELDT, Ronald L. Medical Workplace Violence. Primary Care Update OB/GYNs, Nova York, v. 8, p. 127-131, 2001.

KIND, Luciana. Notas para o trabalho com a técnica de grupos focais. Psicologia em Revista, Belo Horizonte, v. 10, n. 15, p. 124136, jun. 2004.

KRUG, Etienne G. et al. (org.). World Report on Violence and Health. Genebra: World Health Organization, 2002.

LANZA, Marilyn L. How Nurses React to Patient Assault. Journal of Psychosocial Nursing and Mental Health Services, v. 23, n. 6, p. 6-11, 1985

LANZA, Marilyn L. The Reactions of Nursing Staff to Physical Assault by a Patient. Hospital and Community Psychiatry, v. 31, n. 1, p. 44-47, 1983.

LEATHER, Phil. Workplace Violence: Scope, Definition and Global Context. In: COOPER, Cary L.; SWANSON, Naomi (org.). Work- place Violence in the Health Sector: State of the Art. Manchester: Organização Internacional do Trabalho, 2001.

LEBLANC, Manon Mireille; KELLOWAY, E. Kevin. Predictors and Outcomes of Workplace Violence and Aggression. Journal of Applied Psychology, v. 87, n. 3, p. 444-453, 2002.

MACHADO, Jorge M. H.; MINAYO GOMEZ, Carlos. Acidentes de trabalho: uma expressão da violência social. Cadernos de Saúde Pública, Rio de Janeiro, v. 10, supl. 1, p. 7487, 1994.

MINAYO, Maria Cecília de S. A violência social sob a perspectiva da saúde pública. Cadernos de Saúde Pública, Rio de Janeiro, v. 10, supl. 1, p. 7-18, 1994.

MINAYO, Maria Cecília de S.; SOUZA, Edinilsa Ramos de. Violência e saúde como um campo interdisciplinar e de ação coletiva. História, Ciências, Saúde-Manguinhos, Rio de Janeiro, v. 4, n. 3, p. 513-531, nov. 1997-fev. 1998.

ORGANIZAÇÃO INTERNACIONAL DO TRABALHO; INTERNATIONAL COUNCIL OF NURSES; ORGANIZAÇÃO MUNDIAL DA SAÚDE. Framework Guidelines for Addressing Workplace Violence in the Health Sector. Genebra: Organização Internacional do Trabalho, 2002.

ORGANIZAÇÃO INTERNACIONAL DO TRABALHO; INTERNATIONAL COUNCIL OF NURSES; ORGANIZAÇÃO MUNDIAL DA SAÚDE. Workplace Violence in the Health Sector - Country Case Studies Research Instruments. Research Protocol. Genebra: Organização International do Trabalho, 2003a.

ORGANIZAÇÃO INTERNACIONAL DO TRABALHO; INTERNATIONAL COUNCIL OF NURSES; ORGANIZAÇÃO MUNDIAL DA SAÚDE; PUBLIC SERVICES INTERNATIONAL. Workplace Violence in the Health Sector - Country Case Studies Research Instruments. Guidelines for Focus Group Discussion. Genebra: Organização International do Trabalho, 2003b. 
ORGANIZAÇÃO INTERNACIONAL DO TRABALHO; INTERNATIONAL COUNCIL OF NURSES; ORGANIZAÇÃO MUNDIAL DA SAÚDE; PUBLIC SERVICES INTERNATIONAL. Violence in the Health Sector. Country Case Studies: Brazil, Bulgaria, Lebanon, Portugal, South Africa, Thailand and an Additional Australian Study. Genebra: Organização Internacional do Trabalho, 2003c.

PALÁCIOS, Marisa et al. Workplace Violence in the Health Sector. Country Case Study - Brazil. Genebra: Organização Internacional do Trabalho, 2003.

PEIXOTO, Tereza Cristina; BATISTA, Cássia Beatriz. Humaniza SUS: problematizando a humanização na saúde, a sociedade. In: COLÓQUIO INTERNACIONAL DE PSICOSSOCIOLOGIA E SOCIOLOGIA CLÍNICA, 13. Anais... Belo Horizonte, Universidade Federal de Minas Gerais, 2009.

ROGERS, Kimberley-Ann; KELLOWAY, E. Kevin. Violence at Work: Personal and Organizational Outcomes. Journal of Occupational Health Psychology, v. 2, n.1, p. 63-71, 1997.

ROSE, Suzanna; TEHRANI, Noreen. History, Methods and Development of Psychological Debriefing. In: THE BRITISH PSYCHOLOGICAL SOCIETY. Psychological Debriefing. Londres: The British Psychological Society, 2002.

RYAN, Jane A.; POSTER, Elizabeth C. The Assaulted Nurse: Short-term and Long-term responses. Archives of Psychiatric Nursing, v. 3, n. 6, p. 323-331, 1989.
SANTOS JÚNIOR, Éber A.; DIAS, Elizabeth C. Violência no trabalho: uma revisão da literatura. Revista Brasileira de Medicina do Trabalho, v. 2, n. 1, jan.-mar. 2004.

SILVEIRA, Andréa M. A prevenção da violência - desafio para todos. Revista Médica de Minas Gerais, v. 16, n. 4, p. 86-91, 2007.

SCHAT, Aaron C. H.; KELLOWAY, E. Kevin. Effects of Perceived Control on the Outcomes of Workplace Aggression and Violence. Journal of Occupational Heath Psychology, v. 5, n. 3, p. 386-402, 2000.

SCHNIEDEN, Vivienne. Violence Against Doctors. British Journal of Hospital Medicine, v. 50, n. 1, 9, 1993.

TOSCANO, Guy; WEBER, William. Violence in the Workplace: Patterns of Fatal Workplace Assaults Differ from those of Nonfatal Ones. Washington (DC): Bureau of Labor Statistic, 1995. p. 43-50.

TOSCANO, Guy; WINDAU, Janice. The Changing Character of Fatal Work Injuries. Monthly Labor Review, v. 117, n. 10, p. 1728, 1994.

TRAJANO, Ana Rita C. Construindo a cultura da paz e da não violência no campo da saúde pública. Revista Médica de Minas Gerais, v. 16, n. 4, p. 92-96, 2007.

Recebido em 01/09/2010

Aprovado em 27/10/2010 